\title{
Effects of Baclofen on Cocaine Self-Administration: Opioid- and Nonopioid-Dependent Volunteers
}

\author{
Margaret Haney*,', Carl L Hart' and Richard W Foltin' \\ 'Department of Psychiatry, College of Physicians and Surgeons of Columbia University and the Division on Substance Abuse, New York State \\ Psychiatric Institute, New York, NY, USA
}

\begin{abstract}
Preclinical and clinical studies suggest that $\mathrm{GABA}_{\mathrm{B}}$ receptor agonists selectively decrease cocaine use. The behavioral mechanism for the interaction between baclofen and cocaine in humans is not known, nor have its effects been characterized in individuals dependent on both cocaine and methadone. The objective of this study is to determine how maintenance on baclofen influences smoked cocaine's reinforcing and subjective effects, mood and cocaine craving prior to and after the initiation of cocaine use in cocaine-dependent volunteers with and without concurrent opioid dependence. Nontreatment-seeking volunteers ( 10 nonopioid dependent; seven methadone maintained), residing on an in-patient research unit for 2 I days, were maintained on each baclofen dose $(0,30,60 \mathrm{mg}$ po) for 7 days. A smoked cocaine dose-response curve $(0,12,25,50 \mathrm{mg})$ was determined twice: on days 3-4 and days 6-7 of each baclofen maintenance condition. Cocaine sessions began with a sample trial, when participants smoked the cocaine dose available that session, and five choice trials, when participants chose between smoking the available cocaine dose or receiving one $\$ 5$ merchandise voucher. The results show that in the nonmethadone group, baclofen $(60 \mathrm{mg})$ decreased self-administration of a low cocaine dose (I2 mg). In the methadone group, baclofen decreased craving for cocaine. In both groups, baclofen decreased cocaine's effects on heart rate. Baclofen did not alter cocaine's robust subjective effects (eg 'High,' 'Stimulated') for either group. The results from this laboratory study appear consistent with clinical evidence showing that baclofen decreases cocaine use in nonopioid-dependent patients seeking treatment for cocaine dependence. The distinct pattern of effects in methadone-maintained participants suggests baclofen may not be effective in opioid-dependent cocaine users.
\end{abstract}

Neuropsychopharmacology (2006) 3 I, I 8|4- I821. doi: | 0.1038/sj.npp. I 300999; published online I I January 2006

Keywords: crack cocaine; GABA; self-administration; craving; methadone

\section{INTRODUCTION}

There are estimated to be over 3 million individuals dependent on cocaine in the United States (Substance Abuse and Mental Health Services Administration, 2003). Yet in contrast to most drugs of abuse, there are currently no medications available to facilitate behavioral treatment for cocaine dependence. One neurochemical approach that has shown promise in preclinical and clinical studies with cocaine is to increase activity of the inhibitory neurotransmitter, $\gamma$-aminobuytric acid (GABA; see Cousins et al, 2002). The primary mechanism by which GABA is presumed to decrease cocaine's effects is by decreasing its influence on mesolimbic dopamine activity. Cocaine increases extracel-

*Correspondence: Dr M Haney, New York State Psychiatric Institute, Columbia University, I05I Riverside Drive, Unit 120, New York, NY 10032, USA, Tel: + I 212543 6539, Fax: + I 212543 599I, E-mail:mh235@columbia.edu

Received 22 August 2005; revised 25 October 2005; accepted 26 October 2005

Online publication: I November 2005 at http://www.acnp.org/citations/ Npp 1 I $0105050527 /$ default.pdf lular dopamine levels in the nucleus accumbens, a primary end point for the mesolimbic dopamine pathway originating in the ventral tegmental area (VTA), and this increase in dopamine contributes to cocaine's reinforcing effects (see Koob and Nestler, 1997). GABAergic neurons decrease dopamine release by tonically inhibiting firing of dopamine neurons in the VTA.

Specifically, agonists that bind the $\mathrm{GABA}_{\mathrm{B}}$ receptor subtype have been shown to modulate cocaine effects. $\mathrm{GABA}_{\mathrm{B}}$ receptors are localized on dopamine neurons in the VTA, and microdialysis studies demonstrate that administration of the $\mathrm{GABA}_{\mathrm{B}}$ receptor agonist, baclofen, into the VTA decreases extracellular dopamine levels in the nucleus accumbens and prefrontal cortex (Westerink et al, 1996, 1998; Klitenick et al, 1992). Baclofen also dose dependently decreases both cocaine-induced elevations in extracellular dopamine in the nucleus accumbens (Fadda et al, 2003), and cocaine's behavioral effects in laboratory animals. Administration of baclofen, either systemically (Roberts et al, 1996; Roberts and Andrews, 1997, Brebner et al, 2000a) or locally (Shoaib et al, 1998; Brebner et al, 2000b) decreases cocaine self-administration, particularly for low 
cocaine doses. These effects are pharmacologically specific, in that they are blocked by selective $\mathrm{GABA}_{B}$ antagonists (Brebner et al, 2002b). Baclofen also appears to be behaviorally specific, in that it decreases responding for cocaine at doses that do not alter food intake, even when responding for food is maintained at a high rate (Roberts et al, 1996; Shoaib et al, 1998; Brebner et al, 2000a; but see Weerts et al, 2005).

In addition to decreasing cocaine's direct reinforcing effects, baclofen also decreases drug-seeking following exposure to cocaine-paired stimuli (Campbell et al, 1999; Di Ciano and Everitt, 2003); this effect is presumably mediated by a decrease in the effect of cocaine-paired cues on dopamine release (Gerasimov et al, 2001). These preclinical data predict baclofen would decrease the likelihood of cocaine relapse, a finding that has been supported. In a randomized clinical pilot study (Shoptaw et al, 2003) combining medications with cognitive-behavioral therapy, cocaine-dependent patients maintained on baclofen $(20 \mathrm{mg}$ TID; $n=35$ ) used significantly less cocaine than those maintained on placebo $(n=35)$. It appears that baclofen was most effective in individuals who were heavy cocaine users prior to the onset of treatment, as opposed to more episodic cocaine users.

The behavioral mechanism by which baclofen interacts with cocaine in humans is unknown. The objective of the present study was two-fold. The first objective was to determine how baclofen alters the effects of smoked cocaine under controlled laboratory conditions. Laboratory models utilizing smoked cocaine are particularly relevant for evaluating potential cocaine pharmacotherapy because cocaine smokers fare worse in treatment than those who use cocaine intranasally (Nuñes et al, 1995). The following questions were asked: does baclofen alter cocaine's reinforcing or subjective effects directly, does it decrease cocaine craving prior to or after the initiation of cocaine use, or does it alter cocaine self-administration nonspecifically, for example by increasing sedation?

The second objective was to assess baclofen's effects in methadone-maintained, cocaine-dependent volunteers in addition to a group who was not dependent on opioids. A significant percentage $(40 \%)$ of methadone-maintained patients meet criteria for cocaine dependence (Hser et al, 1998; Rosenblum et al, 1999), and cocaine use has been shown to compromise drug treatment by increasing the likelihood of heroin use and behaviors that increase the risk of HIV (Hartel et al, 1995). Cocaine use also increases the likelihood patients will drop out of methadone treatment (DeMaria et al, 2000). Thus, characterizing baclofen's effects in this population is highly relevant clinically.

In the present study, the dose-dependent effects of baclofen maintenance on smoked cocaine self-administration, cocaine craving, subjective-effects ratings, and cardiovascular effects were studied in two populations of cocaine-dependent volunteers (neither of whom was seeking treatment for their cocaine use): those maintained on methadone and those who were not. All participants were maintained on three doses of baclofen in a placebocontrolled, crossover design. Self-administration of cocaine was tested repeatedly under each baclofen maintenance condition, and alternatives to drug-taking were available, just as they are outside of the laboratory.

\section{METHODS}

\section{Participants}

Cocaine-dependent research volunteers were solicited through word-of-mouth referral and newspaper advertisements in New York, NY. All volunteers were current crack cocaine users who were not interested in treatment, and who had no major psychiatric or medical disorders. Table 1 presents their demographic information. All participants met DSM-IV criteria for cocaine dependence (and tested positive for benzoylecgonine during screening), and the methadone-maintained participants were opioid dependent as well. None of the volunteers met criteria for dependence on any other illicit drug or on alcohol. No participant had a major affective illness or schizophrenia. None had a significant medical history for heart disease or hypertension, and no female was pregnant. Each participant signed a consent form, approved by The New York State Psychiatric Institute Institutional Review Board. The consent form described the study, outlined the possible risks, indicated that participants would be maintained on varying doses of baclofen, and that smoked cocaine would be available. All study volunteers were compensated for their participation ( $\$ 25 /$ day plus a bonus of $\$ 25 /$ day if they completed the study).

Three additional nonopioid-dependent participants were enrolled in the protocol but did not complete it: one left the study due to a family emergency, one was discharged for failing to comply with study protocol, and one was discontinued due to electrocardiogram abnormalities; these abnormalities were classified as normal variants by the study cardiologist, but their presence made it too difficult to interpret cocaine's cardiovascular effects.

Table I Demographic Characteristics of Study Participants

\begin{tabular}{lcc}
\hline & Nonmethadone & Methadone \\
\hline Sex (female: male) & $1 / 9$ & $2 / 7$ \\
Age (years) & $37.5 \pm 4.7$ & $35.0 \pm 7.1$ \\
Race/ethnicity (black/white/hispanic) & $9 / 0 / 1$ & $4 / 1 / 2$ \\
Cocaine use (\# days/week) & $4.5 \pm 1.6$ & $4.4 \pm 1.3$ \\
Dollars spent on cocaine/week & $* \$ 357 \pm 258$ & $\$ 187 \pm 89 /$ week \\
Years of cocaine use & $12.3 \pm 4.2$ & $11.3 \pm 4.4$ \\
Cigarette smokers (\#) & 10 & 7 \\
Cigarettes/day & $8.0 \pm 3.6$ & $18.3 \pm 11.0$ \\
Alcohol drinkers (\#) & 6 & 6 \\
Alcohol: drinks/week & $6.6 \pm 4.9$ & $15.3 \pm 16.4$ \\
Marijuana smokers (\#) & 4 & 0 \\
Marijuana cigarettes/week & $3.0 \pm 0.6$ & $\mathrm{NA}$ \\
Heroin users (\#) & 0 & 3 \\
Dollars spent on heroin/occasion & $\mathrm{NA}$ & $\$ 19 \pm 12$ \\
Education (years) & $12.0 \pm 1.3$ & $13.3 \pm 1.9$ \\
\hline
\end{tabular}

NA = not applicable.

Note: Data are presented as means $( \pm S D)$ or as frequency or percentage. Methadone dose for the methadone group ranged from 70 to $140 \mathrm{mg} /$ day (average dose $95 \mathrm{mg}$ ).

*As a point of reference, the cost of street cocaine in New York City at the time of the study was $\$ 30-40 / g$. 


\section{Drugs}

Baclofen. Baclofen (Lioresal ${ }^{\circledR}$ ) is a centrally acting muscle relaxant FDA approved for the treatment of muscle spasms. It is rapidly absorbed after oral administration and has a half-life in plasma of 3-4 h. Baclofen (10, $20 \mathrm{mg}$ TID) and matching placebo, prepared by the Presbyterian Hospital Manufacturing Pharmacy, were orally administered under double-blind conditions at 0800,1400 and 2200 for 7 consecutive days each. Cocaine self-administration sessions began on the 3rd day of each baclofen maintenance condition. Dose order was counter-balanced. On the 1st day of each active baclofen dosing condition, half the maintenance dose was administered TID, for example $5 \mathrm{mg}$ TID for the $10 \mathrm{mg}$ TID maintenance dose condition and $10 \mathrm{mg}$ TID for the $20 \mathrm{mg}$ TID maintenance condition.

Cocaine. The doses of cocaine base $(0,12,25,50 \mathrm{mg})$, derived from cocaine hydrochloride (purchased from Mallinckrodt) were prepared by the Presbyterian Hospital Manufacturing Pharmacy (Foltin et al, 1990). The order of cocaine dosing was randomized, except that for safety reasons, the first dose of smoked cocaine administered in the study was never the highest dose $(50 \mathrm{mg})$ for any participant. During cocaine administration, participants were presented with cocaine base in a glass pipe stem fitted with smoke screens. A research nurse held a flame on the cocaine and participants were instructed to take one large inhalation and to hold it as long as they would outside the laboratory. Participants wore eye masks during cocaine administration so that they were blinded to the contents of the pipe. For the placebo cocaine condition, blindfolded participants smoked from an empty glass pipe stem.

\section{Procedure}

Participants resided on the Irving Center for Clinical Research in The Presbyterian Hospital for the duration of the 21-day study. They had access to television, radio, and video-taped movies in their hospital rooms. Participants were permitted to smoke cigarettes ad libitum, except during laboratory sessions. No one was permitted to leave the unit unescorted, and visitors were prohibited.

As shown in Table 2, a total of 24 cocaine selfadministration sessions occurred over the course of the study, each $2 \mathrm{~h}$ long: four doses of smoked cocaine were each tested twice during maintenance on each baclofen dose. Procedures for the morning (0900) and afternoon sessions (0300) were identical, except for the dose of cocaine tested. During self-administration sessions, participants were seated in a comfortable lounge chair in front of a Macintosh ${ }^{\circledR}$ computer used to complete subjective-effects questionnaires and to indicate choice between cocaine and vouchers. Blood was withdrawn through an 18-gauge catheter (Quik-Cath ${ }^{\circledR}$, Travenol Laboratories, Deerfield, IL) inserted into an arm or hand vein. The intravenous lines were kept patent by an infusion of a physiological saline solution. Electrocardiograms were continuously monitored via chest electrodes $\left(\mathrm{MAC} \mathrm{PC}^{\circledR}\right.$, Marquette Electronics, Milwaukee, WI) while heart rate and systolic and diastolic blood pressure were recorded every $2 \mathrm{~min}$ (Sentry II - Model 6100 automated vital signs monitor, NBS
Table 2 Representative Schedule of Experimental Design

\begin{tabular}{|c|c|c|c|}
\hline \multirow[b]{2}{*}{ Day } & \multicolumn{2}{|c|}{ Cocaine sessions } & \multirow[b]{2}{*}{$\begin{array}{c}\text { Baclofen dose } \\
\text { (mg/day) }\end{array}$} \\
\hline & 0900 & 0300 & \\
\hline Move-in & - & - & - \\
\hline । & - & - & 30 \\
\hline 2 & - & - & 60 \\
\hline 3 & 12 & 0 & 60 \\
\hline 4 & 25 & 50 & 60 \\
\hline 5 & - & - & 60 \\
\hline 6 & 25 & 12 & 60 \\
\hline 7 & 50 & 0 & 60 \\
\hline 8 & - & - & 0 \\
\hline 9 & - & - & 0 \\
\hline 10 & 50 & 12 & 0 \\
\hline II & 0 & 25 & 0 \\
\hline 12 & - & - & 0 \\
\hline 13 & 12 & 50 & 0 \\
\hline 14 & 25 & 0 & 0 \\
\hline 15 & & & 15 \\
\hline 16 & - & - & 30 \\
\hline 17 & 25 & 50 & 30 \\
\hline 18 & 12 & 0 & 30 \\
\hline 19 & - & - & 30 \\
\hline 20 & 0 & 12 & 30 \\
\hline 21 & 50 & 25 & 30 \\
\hline Move-out & - & - & - \\
\hline
\end{tabular}

Note: Morning and afternoon cocaine sessions lasted $2 \mathrm{~h}$.

Medical, Costa Mesa, CA) beginning 20 min prior to cocaine administration.

Each self-administration session consisted of six trials. Participants were instructed that they would be repeatedly given the choice to smoke a dose of cocaine or receive a $\$ 5$ merchandise voucher redeemable at specific stores, payable upon discharge. Sessions began with one 'sample' trial, where participants responded on a keyboard under a fixed ratio schedule (FR200) to receive the cocaine dose available that day. Subsequently, there were five 'choice' trials, spaced 14-min apart, in which participants had the opportunity to self-administer the same dose of cocaine as the sample dose, or receive a voucher. Each trial was indicated by a visual cue on the computer screen. Participants selected the left or right option with their computer mouse (illuminating the square associated with that position), and pressed the spacebar or enter key on their computer keyboard until they completed the response requirement (FR200) and the message 'Left (or Right) Option Chosen' appeared at the bottom of the screen. Participants were instructed that the left option would be associated with cocaine and the right option would be associated with vouchers. Blood for determination of cocaine plasma level was drawn at baseline, 4 and $12 \mathrm{~min}$ after the 'sample' cocaine administration. The session ended $30 \mathrm{~min}$ after the last option delivery. 
Throughout the session, participants were monitored via a one-way mirror by research nurses located in the adjacent room, with whom they could communicate via an intercom system. Neither cocaine nor vouchers were given on any trial where cardiovascular activity was above the criteria for safe drug administration (SP $>160 \mathrm{mmHg}, \mathrm{DP}>100 \mathrm{mmHg}$, HR $>$ (220-participant's age) 0.85$)$.

\section{Subjective-Effects Battery}

A computerized subjective-effects questionnaire, comprising a series of $100-\mathrm{mm}$ visual analog scales (VAS) labelled 'Not at all' $(0 \mathrm{~mm})$ at one end and 'Extremely' at the other end, was completed eight times: prior to the first cocaine administration, $4 \mathrm{~min}$ after each option was delivered, and $30 \mathrm{~min}$ after the last option of the session. Of these VAS, 18 were labelled with adjectives describing mood, for example 'I feel...' 'Stimulated.' In order to reduce the number of dependent variables analyzed, cluster analysis was accomplished on these 18 mood adjectives, yielding four clusters (see Evans et al, 2002). An additional cluster analysis was carried out for three adjectives rating the dose of cocaine. Each cluster score was derived by taking the arithmetic mean of the items in the cluster. The Good Drug Effect cluster comprised three items: 'Good Drug Effect,' 'High,' and 'Stimulated.' The Bad Drug Effect cluster comprised seven items: 'Anxious,' 'Bad Drug Effect,' 'Confused,' 'Depressed,' 'Irritable,' 'Sedated,' and 'Tired.' The Social cluster comprised five items: 'Social,' 'Talkative', 'Selfconfident,' 'Alert,' and 'Friendly.' The Focused/Calm cluster comprised 'Able to Concentrate' and 'Calm.' The Cocaine Rating cluster comprised three ratings of the cocaine dose: The choice was ...'High Quality,' 'Potent,' and 'I Liked the Choice.' Four VAS operationalized drug craving and were labelled 'I want...' 'Cocaine,' 'Heroin,' 'Alcohol,' and 'Tobacco.' The last VAS asked participants to indicate how much they would pay for the dose of cocaine they had just received, anchored with $\$ 0$ and $\$ 25$. Thus, a total of 10 ratings were analyzed.

\section{Data Analysis}

The effects of baclofen maintenance on the number of choices to smoke cocaine within a session, and the subjective effects, cardiovascular measures and plasma cocaine levels were analyzed using planned comparisons generated by a repeated measures Analysis of Variance. There were four within-subjects factors: baclofen dose $(0$, $30,60 \mathrm{mg} /$ day $)$, cocaine dose $(0,12,25,50 \mathrm{mg})$, replication (first and second cocaine dose-response determination within each maintenance condition), and time of measurement. The planned comparisons were single degree of freedom comparisons that used the error term for the baclofen dose $\times$ cocaine dose $\times$ time interaction. Eight planned comparisons were completed for each measure: Each active baclofen dose $(30,60 \mathrm{mg} /$ day $)$ was compared with placebo baclofen for each dose of cocaine $(0,12,25$, $50 \mathrm{mg}$ ). Mean subjective-effects data obtained $4 \mathrm{~min}$ after each option delivery, peak cardiovascular data obtained 2-12 min after each option delivery, and plasma cocaine obtained 4 and 12 min after the first cocaine administration of the session were analyzed. Methadone and nonmethadone groups were analyzed separately because the methadone group reported that they smoked almost half the amount of cocaine as the nonmethadone group, and there was limited power to conduct between-group comparisons. $p$-values less than 0.05 were considered statistically significant, except for subjective-effects data, which had a stricter criterion $(p<0.01)$ for statistical significance due to the larger number of comparisons made. Huynh-Feldt corrections were used, when appropriate.

\section{RESULTS}

\section{Self-Administration}

Figures 1 and 2 portray selected effects as a function of cocaine dose, baclofen dose and participant group. The top panels of Figure 1 show that cocaine self-administration increased as a function of cocaine dose $(p<0.001)$. In the nonmethadone group, maintenance on baclofen $(60 \mathrm{mg})$ significantly decreased the number of times the $12 \mathrm{mg}$ dose of cocaine was self-administered as compared to placebo maintenance $(\mathrm{F}(1,54)=5.05, p<0.05)$. Baclofen did not alter cocaine self-administration in the methadone group.

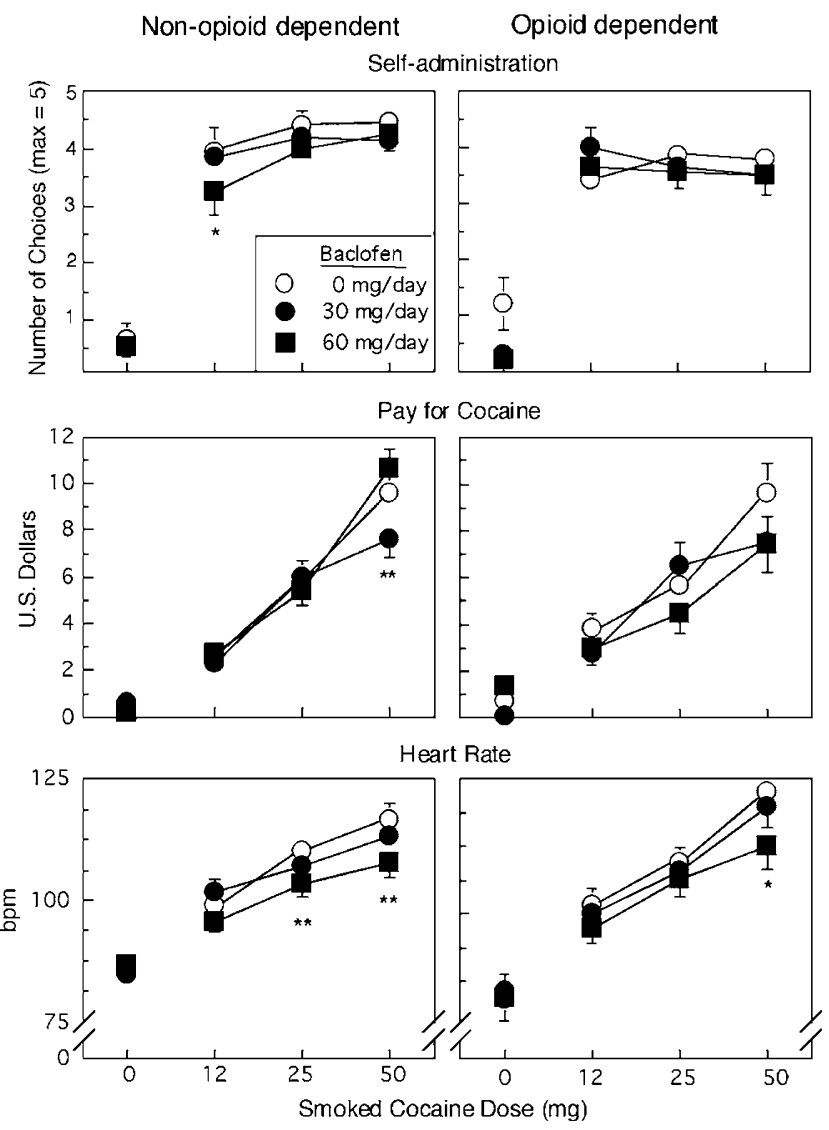

Figure I Data for the nonopioid-dependent $(n=10)$ and opioiddependent $(n=7)$ groups are portrayed as a function of cocaine dose and baclofen maintenance condition. Error bars represent \pm standard error of the mean (SEM). Asterisks denote a significant difference between an active dose of baclofen and placebo baclofen at that dose of cocaine $(* p<0.05$, *** $p<0.0$ I). 


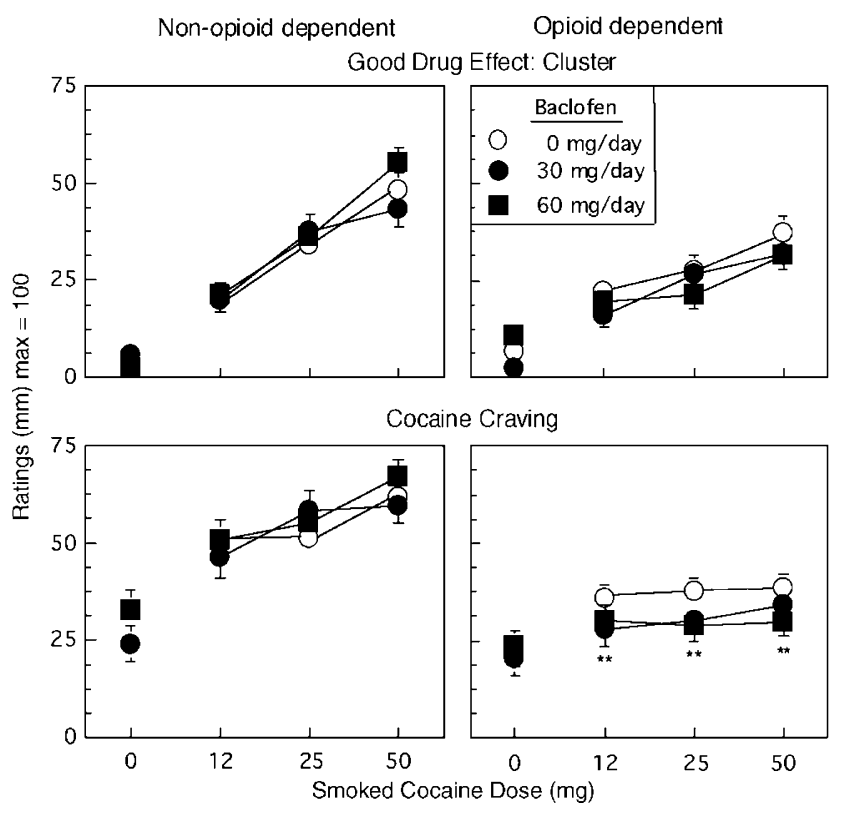

Figure 2 See Figure I for details.

\section{Subjective Effects Measures}

The middle panels of Figure 1 show that ratings of the amount of money both groups would pay for cocaine increased as a function of cocaine dose $(p<0.001)$, and that ratings for highest dose of cocaine $(50 \mathrm{mg})$ were significantly decreased by the low dose of baclofen $(30 \mathrm{mg})$ in the nonmethadone group only $(\mathrm{F}(1,378)=50.79, p<0.0001)$. Baclofen did not alter the robust, cocaine dose-dependent increases in cluster ratings of Good Drug Effect (Figure 2; top panel) and Cocaine Rating (data not shown) for either group.

\section{Drug Craving}

The bottom panel of Figure 2 shows that ratings of cocaine craving were significantly increased by cocaine in the nonopioid-dependent group only $(p<0.001)$, and baclofen did not influence this effect. In the methadone group, cocaine did not significantly increase cocaine craving, yet baclofen $(30 \mathrm{mg})$ significantly decreased these ratings following the 12 and $25 \mathrm{mg}$ doses $(12 \mathrm{mg}: \mathrm{F}(1,378)=19.52$; $25 \mathrm{mg}$ : $\mathrm{F}=16.35, p<0.001)$; the higher baclofen dose $(60 \mathrm{mg})$ significantly decreased cocaine craving following all active cocaine doses $(12 \mathrm{mg}: \mathrm{F}(1,378)=10.75 ; 25 \mathrm{mg}$ : $\mathrm{F}=22.86$; 50 mg: $\mathrm{F}=21.70 ; p<0.0002)$.

\section{Cardiovascular Measures}

For the participants who completed the study, the reinforcer was withheld on 10 of the 2448 trials $(0.4 \%)$ due to either temporary elevations in blood pressure, or because participants did not complete the response requirement (FR200) in the allotted time.

As portrayed in the bottom panels of Figure 1, cocaine significantly increased mean peak heart rate in both groups $(p<0.0001)$. The highest baclofen dose $(60 \mathrm{mg})$ significantly
Table 3 Mean Plasma Cocaine Levels (ng/ml) after a Single Cocaine Administration

\begin{tabular}{|c|c|c|c|c|}
\hline & \multicolumn{4}{|c|}{ Smoked cocaine dose $(\mathrm{mg})$} \\
\hline & 0 & 12 & 25 & 50 \\
\hline \multicolumn{5}{|c|}{ Baclofen (mg/day) } \\
\hline \multicolumn{5}{|c|}{ Nonopioid dependent } \\
\hline 0 & $10.5(3.7)$ & $43.9(4.4)$ & $105.0(10.5)$ & I57.| (12.7) \\
\hline 30 & | $4.7(3.9)$ & $56.0(7.0)$ & $124.8(8.6)$ & | $85.6(\mid 4.0)^{*}$ \\
\hline 60 & $15.0(2.9)$ & $46.7(4.5)$ & $111.3(9.2)$ & I64.6 (1 1.4) \\
\hline \multicolumn{5}{|c|}{ Opioid dependent } \\
\hline 0 & | $8.0(5.1)$ & $92.6(12.0)$ & $127.4(14.1)$ & I76.7 (I8.4) \\
\hline 30 & $10.8(3.3)$ & $61.8(5.3)$ & $127.9(12.0)$ & $186.6(17.1)$ \\
\hline 60 & $17.8(3.7)$ & $86.6(8.3)$ & $127.0(13.5)$ & $228.5(22.4)^{*}$ \\
\hline
\end{tabular}

Note: Data in parentheses represent SEM. Asterisks represent significant differences between baclofen maintenance condition at each dose of cocaine. $* p<0.01$.

decreased this effect for the higher cocaine doses in both the nonmethadone group $(25 \mathrm{mg}: \mathrm{F}(1,54)=8.27 ; 50 \mathrm{mg}$ : $\mathrm{F}=14.92, \quad p<0.01)$ and the methadone group (50 mg: $\mathrm{F}(1,54)=6.78, p<0.02)$. Cocaine also significantly increased systolic pressure by $30-40 \mathrm{mmHg}$ and diastolic pressure by $15-25 \mathrm{mmHg}$ for both groups $(p<0.0001$; data not shown). Baclofen (60 mg) decreased systolic pressure by approximately $7 \mathrm{mmHg}$ following $50 \mathrm{mg}$ cocaine in the nonmethadone group as compared to placebo maintenance $(\mathrm{F}(1,54)=5.40, p<0.03)$.

\section{Plasma Cocaine}

Plasma levels 4 and $12 \mathrm{~min}$ following the first cocaine 'sample' dose of each session were obtained for all but one participant (in the nonmethadone group). As shown in Table 3, plasma cocaine levels following the first dose administration increased significantly as a function of cocaine dose for both groups $(p<0.0001)$. At the highest dose of cocaine $(50 \mathrm{mg})$, plasma cocaine levels were significantly increased by $30 \mathrm{mg}$ baclofen in the nonmethadone group $(\mathrm{F}(1,96)=11.04, p<0.004)$, and by $60 \mathrm{mg}$ baclofen in the methadone group $(\mathrm{F}(1,96)=20.30$, $p<0.002)$.

\section{DISCUSSION}

The present findings demonstrate that maintenance on the $\mathrm{GABA}_{\mathrm{B}}$ agonist, baclofen, decreased self-administration of a low dose of smoked cocaine $(12 \mathrm{mg})$ in nonopioiddependent cocaine smokers. Baclofen also decreased the estimated dollar value of a high dose of cocaine $(50 \mathrm{mg})$ in these participants, although the effect occurred at the low but not the high baclofen dose. This is the first study to test baclofen's effects in individuals dependent on both cocaine and opioids. In this population, baclofen dose dependently decreased cocaine craving, but did not alter its primary 
reinforcing and subjective effects. For both groups of participants, baclofen dose dependently decreased the effects of higher cocaine doses $(25,50 \mathrm{mg})$ on heart rate.

The results from this laboratory study appear consistent with a clinical pilot study showing that baclofen decreased cocaine use in nonopioid-dependent patients seeking treatment for their cocaine use (Shoptaw et al, 2003). Other GABAergic medications have also shown promise clinically: maintenance on indirect GABA agonists such as topiramate (Kampman et al, 2004), and tiagabine (Gonzalez et al, 2003) decreased cocaine use in placebo-controlled clinical trials, while $\gamma$ vinyl-GABA improved rates of cocaine abstinence in open-label trials (Brodie et al, 2003, 2005).

Baclofen's effects in the laboratory were small in magnitude, but a decrease in cocaine self-administration in individuals who are unequivocal about their cocaine use is noteworthy. The objective of this human laboratory model is to assess the direct effects of potential treatment medications on highly reinforcing doses of smoked cocaine. For ethical reasons, only individuals who are not interested in treatment for their cocaine use can participate in these studies. This model is an important precursor to exposing hundreds of treatment seekers to a medication with unknown effects on cocaine use. Cocaine self-administration is a behavior that is difficult to disrupt either in the laboratory or clinically. Medications rarely decrease cocaine self-administration, even when they decrease cocaine's effects on ratings such as 'High' and 'Good Drug Effect' (see Fischman et al, 1990; Haney et al, 1998, 1999; Hart et al, 2004). Although the laboratory model cannot be validated in lieu of a clinically effective treatment medication for cocaine dependence, one of the few other medications that altered cocaine self-administration in the laboratory also predicted clinical effects: maintenance on the dopamine D1 receptor antagonist, ecopipam, significantly increased cocaine (12 mg) self-administration (Haney et al, 2001) and was found to be ineffective clinically (see Grabowski et al, 2000). Thus, we suggest that a decrease in cocaine self-administration, albeit a small one, is likely to predict a positive clinical outcome.

There might have been more robust effects on cocaine self-administration if baclofen had been administered for several weeks prior to cocaine availability. Single acute doses of baclofen had no effect when combined with intranasal cocaine in a human laboratory study (Lile et al, 2004), and in the present study, baclofen's effects in combination with smoked cocaine were determined after only 3-7 days of baclofen administration. Clinically, baclofen and other GABAergic medications are most effective in decreasing cocaine use after several weeks of maintenance. Baclofen-treated patients were most likely to provide urines free from cocaine metabolites after 3-8 weeks of study participation (Shoptaw et al, 2003). Similarly, the GABA agonist, tiagabine, had no effect on cocaine use in a clinical sample until at least 3 weeks of administration (Gonzalez et al, 2003).

Baclofen did not alter the self-administration of higher cocaine doses, which is consistent with preclinical animal data (eg Campbell et al, 1999; Roberts et al, 1996). Given that baclofen's effects are surmountable at higher cocaine doses, some have argued that this medication is not best suited to interrupt ongoing, heavy cocaine use (which was modelled in the current study), but rather may be more useful in preventing relapse (Brebner et al, 2002a). Baclofen decreased cocaine-induced reinstatement of drug seeking in laboratory animals (Campbell et al, 1999), and dose dependently decreased ratings of cocaine craving in the methadone group, which may support this notion. Decreases in craving in the methadone group did not result in less self-administration in this study or in earlier studies (eg Fischman et al, 1990), but it may be possible that reduced cocaine-induced craving would decrease the likelihood that a lapse (small use of cocaine) would precipitate a relapse (return to preabstinent levels of drug use) in treatment seekers. The significance of baclofen's effects on craving in the methadone-maintained volunteers remains to be determined, particularly since craving was not increased by cocaine alone.

For both groups, baclofen increased plasma cocaine levels at the $50 \mathrm{mg}$ condition. This effect occurred at the high baclofen dose in the methadone group and at the low baclofen dose in the nonmethadone group. A similar effect has been reported with disulfiram (McCance-Katz et al, 1998), which also has shown promise clinically for cocaine dependence (Carroll et al, 2004). Disulfiram also altered the profile of cocaine's effects which baclofen did not do. In fact, there was little evidence that baclofen had intrinsic subjective effects (eg 'Sedated' and 'Tired') or enhanced cocaine-related ratings (eg 'Anxious'). This latter point is important, as some preclinical studies described above note the nonspecificity of baclofen's effects with regard to cocaine.

There were important differences in baclofen's effects in the methadone- and nonmethadone participants: decreases in cocaine's reinforcing effects for one group, and while only a decrease in cocaine craving in the other group. Increased craving following cocaine administration is a consistent effect in cocaine users (eg Haney et al, 1998, 2001; Fischman et al, 1990), yet the methadone group did not show this effect. Although not directly compared the methadone group had higher plasma cocaine levels than the nonmethadone group regardless of baclofen dose (Table 3 ). The two groups also differed in the quantity of current cocaine use, with the methadone group reporting that they smoked roughly half the amount of cocaine than the nonmethadone group in their natural environment. This suggests different patterns of cocaine intake in the two groups, which may have affected the present findings. Shoptaw et al (2003) reported that baclofen was most effective in decreasing cocaine use in patients who were heavy cocaine users prior to treatment. It is not clear if the cocaine use patterns or the methadone per se contributed to the differential response to cocaine and to baclofen. Further studies directly comparing medication effects in opioid- and nonopioid-dependent cocaine users are needed.

To conclude, the mechanism by which baclofen produced positive clinical effects in a pilot clinical trial (Shoptaw et al, 2003) may be by decreasing the direct reinforcing effects of cocaine, at least for nonopioid-dependent individuals. Baclofen did not alter cocaine's robust subjective effects, that is, 'High' or 'Stimulated,' for either participant group, just as it does not alter cocaine's discriminative stimulus properties in laboratory animals (Munzar et al, 2000; Negus et al, 2000). This pattern contrasts with what we have 
observed for other medications, such as dopaminergic agonists (Haney et al, 1998, 1999), antidepressants (Fischman et al, 1990; Foltin et al, 2003), and anticonvulsants (Hart et al, 2004), which have been shown to alter cocaine's positive subjective effects without affecting cocaine reinforcement. There was no evidence that baclofen produced nonspecific effects, such as increased sedation. Further, baclofen was safely administered in combination with cocaine, and in fact, dose dependently attenuated cocaine's cardiovascular effects. Baclofen also dose dependently decreased cocaine craving, but only in the methadonemaintained participants, for whom cocaine alone did not increase craving. The different pattern of baclofen effects in opioid-dependent volunteers highlights the importance of determining the effect of medications in both subsets of cocaine-dependent populations. Thus, the present data support the use of baclofen in the treatment of cocaine dependence, but suggest that baclofen may not be clinically effective in a methadone-maintained population of cocaine treatment seekers.

\section{ACKNOWLEDGEMENTS}

This research was supported by NIDA Grant DA-06234. Participants resided on the Irving Center for Clinical Research of The Columbia-Presbyterian Medical Center, supported by Grant No. MOI-RR-00645 from the National Institutes of Health. We are grateful for the outstanding nursing assistance of Brenda Fay, Alyce Stephens and Laura Burr, and the medical assistance of Drs Eric Rubin, Eric Collins, and Grace Hennessy. Research assistants, Juliana Blitzer, Martha Jacobs, and Catalina Saldana are also gratefully acknowledged, as are our fellow investigators, Suzanne Vosburg, Nehal Vadhan, and Stephanie Collins.

\section{REFERENCES}

Brebner K, Childress AR, Roberts DCS (2002a). A potential role for $\mathrm{GABA}_{\mathrm{B}}$ agonists in the treatment of psychostimulant addiction. Alcohol Alcohol 37: 478-484.

Brebner K, Froestl W, Roberts DCS (2002b). The $\mathrm{GABA}_{\mathrm{B}}$ antagonist CGP56433A attenuates the effect of baclofen on cocaine but not heroin self-administration in the rat. Psychopharmacology (Berlin) 160: 49-55.

Brebner K, Phelan R, Roberts DCS (2000a). Effect of baclofen on cocaine self-administration in rats reinforced under fixed-ratio 1 and progressive-ratio schedules. Psychopharmacology (Berlin) 148: 314-321.

Brebner K, Phelan R, Roberts DCS (2000b). Intra-VTA baclofen attenuates cocaine self-administration on a progressive ratio schedule of reinforcement. Pharmacol Biochem Behav 66: 857-862.

Brodie JD, Figueroa E, Dewey SL (2003). Treating cocaine addiction: from preclinical to clinical trial experience with $\gamma$-vinyl GABA. Synapse 50: 261-265.

Brodie JD, Figueroa E, Laska EM, Dewey SL (2005). Safety and efficacy of $\gamma$-vinyl GABA (GVG) for the treatment of methamphetamine and/or cocaine addiction. Synapse 55: 122-125.

Campbell UC, Lac ST, Carroll ME (1999). Effects of baclofen on maintenance and reinstatement of intravenous cocaine selfadministration in rats. Psychopharmacology (Berlin) 143: 209-214.

Carroll KM, Fenton LR, Ball SA, Nich C, Frankforter TL, Shi J et al (2004). Efficacy of disulfiram and cognitive behavior therapy in cocaine-dependent outpatients. Arch Gen Psychiatr 61: 264-272.

Cousins M, Roberts D, de Wit $\mathrm{H}$ (2002). $\mathrm{GABA}_{\mathrm{B}}$ receptor agonists for the treatment of drug addiction: a review of recent findings. Drug Alcohol Depend 65: 209-220.

DeMaria Jr PA, Sterling R, Weinstein SP (2000). The effect of stimulant and sedative use on treatment outcome of patients admitted to methadone maintenance treatment. Am J Addict 9: 145-153.

Di Ciano P, Everitt BJ (2003). The $\mathrm{GABA}_{\mathrm{B}}$ receptor agonist baclofen attenuates cocaine-and heroin-seeking behavior by rats. Neuropsychopharmacology 28: 510-518.

Evans SM, Haney M, Foltin RW (2002). The effects of smoked cocaine during the follicular and luteal phases of the menstrual cycle in women. Psychopharmacology (Berlin) 159: 397-406.

Fadda P, Scherma M, Fresu A, Collu M, Fratta W (2003). Baclofen antagonizes nicotine-, cocaine-, and morphine-induced dopamine release in the nucleus accumbens of rat. Synapse 50: 1-6.

Fischman MW, Foltin RW, Nestadt G, Pearlson GD (1990). Effects of desipramine maintenance on cocaine self-administration by humans. J Pharmacol Exp Ther 253: 760-770.

Foltin RW, Fischman MS, Nestadt G, Stromberger H, Cornell EE, Pearlson GD (1990). Demonstration of naturalistic methods for cocaine smoking by human volunteers. Drug Alcohol Depend 26: 145-154.

Foltin RW, Ward AS, Collins ED, Haney M, Hart CL, Fischman MW (2003). Effects of venlafaxine on the subjective, reinforcing and cardiovascular effects of cocaine in opioid-dependent and nonopioid-dependent humans. Exp Clin Psychopharmacol 11: 123-130.

Gerasimov MR, Shiffer WK, Gardner EL, Marsteller DA, Lennon IC, Taylor SJC et al (2001). GABAergic blockade of cocaineassociated cue-induced increases in nucleus accumbens dopamine. Euro J Pharmacol 414: 205-209.

Gonzalez G, Sevarino K, Sofuoglu M, Poling J, Oliveto A, Gonsai K et al (2003). Tigabine increases cocaine-free urines in cocainedependent methadone-treated patients: results of a randomized pilot study. Addiction 98: 1625-1632.

Grabowski J, Rhoades H, Silverman P, Schmitz JM, Stotts A, Creson D et al (2000). Risperidone for the treatment of cocaine dependence: randomized, double-blind trial. J Clin Psychopharmacol 20: 305-310.

Haney M, Collins ED, Ward AS, Fischman MW, Foltin RW (1999). Effect of a selective dopamine D1 agonist (ABT-431) on smoked cocaine self-administration in humans. Psychopharmacology (Berlin) 143: 102-110.

Haney M, Fischman MW, Foltin RW (1998). Effects of pergolide on cocaine self-administration in men and women. Psychopharmacology (Berlin) 137: 15-24.

Haney M, Ward AS, Foltin RW, Fischman MW (2001). Effects of ecopipam, a selective dopamine D1 antagonist, on smoked cocaine self-administration by humans. Psychopharmacology (Berlin) 155: 330-337.

Hart CL, Ward AS, Collins ED, Haney M, Foltin RW (2004). Gabapentin maintenance decreases smoked cocaine-related subjective effects, but not self-administration by humans. Drug Alcohol Depend 73: 279-287.

Hartel DM, Schoenbaum EE, Selwyn PA, Kline J, Davenny K, Klein RS et al (1995). Heroin use during methadone maintenance treatment: the importance of methadone dose and cocaine use. Am J Public Health 85: 83-88.

Hser YI, Anglin MD, Fletcher B (1998). Effect of program modality and client drug dependence history on drug use reduction. J Subst Abuse Treat 15: 513-523.

Kampman KM, Pettinati H, Lunch KG, Dackis C, Sparkman T, Weigley C et al (2004). A pilot trial of topiramate for the treatment of cocaine dependence. Drug Alcohol Depend 75: 233-240.

Klitenick MA, DeWitte P, Kalivas PW (1992). Regulation of somatodendritic dopamine release in the ventral tegmental area 
by opioids and GABA: an in vivo microdialysis study. J Neurosci 12: 2623-2632.

Koob GF, Nestler EJ (1997). The neurobiology of drug addiction. J Neuropsychiatr Clin Neurosci 9: 482-497.

Lile JA, Stoops WW, Allen TS, Glaser PEA, Hays LR, Rush CR (2004). Baclofen does not alter the reinforcing, subject-rated or cardiovascular effects of intranasal cocaine in humans. Psychopharmacology (Berlin) 171: 441-449.

McCance-Katz EF, Kosten TR, Jatlow P (1998). Disulfiram effects on acute cocaine administration. Drug Alcohol Depend 52: 27-39.

Munzar P, Kutkat SW, Miller CR, Goldberg SR (2000). Failure of baclofen to modulate discriminative-stimulus effects of cocaine or methamphetamine in rats. Eur J Pharmacol 408: 169-174.

Negus SS, Mello NK, Fivel PA (2000). Effects of GABA agonists and GABA-A receptor modulators on cocaine discrimination in rhesus monkeys. Psychopharmacology 152: 398-407.

Nuñes EV, McGrath PJ, Quitkin FM, Ocepek-Welikson K, Stewart JW, Koenig $\mathrm{T}$ et al (1995). Imipramine treatment of cocaine abuse: possible boundaries of efficacy. Drug Alcohol Depend 39: 185-195.

Roberts DCS, Andrews MM (1997). Baclofen suppression of cocaine self-administration: demonstration using a discrete trials procedure. Psychopharmacology (Berlin) 131: 271-277.

Roberts DCS, Andrews MM, Vickers GJ (1996). Baclofen attenuates the reinforcing effects of cocaine in rats. Neuropsychopharmacology 15: 417-423.
Rosenblum A, Magura S, Palij M, Foote J, Handelsman L, Stimmel B (1999). Enhanced treatment outcomes for cocaine-using methadone patients. Drug Alcohol Depend 54: 207-218.

Shoaib M, Swanner LS, Beyer CE, Goldberg SR, Schindler CW (1998). The GABAB agonist baclofen modifies cocaine self-administration in rats. Behav Pharmacol 9: 195-206.

Shoptaw S, Yang X, Rotheram-Fuller EJ, Hsieh YCM, Kintaudi PC, Charuvastra VC et al (2003). Randomized placebo-controlled trial of baclofen for cocaine dependence: preliminary effects for individuals with chronic patterns of cocaine use. J Clin Psychiatr 64: 1440-1448.

Substance Abuse and Mental Health Services Administration (2003). Results from the 2002 National Survey on Drug Use and Health: National Findings, Office of Applied Studies, NHSDA Series H-22, DHHS Publication No. SMA 03-3836.

Weerts EM, Froestl W, Griffiths RR (2005). Effects of GABAergic modulators on food cocaine self-administration in baboons. Drug Alcohol Depend 80: 369-376.

Westerink BHC, Kwint H-F, deVries JB (1996). The pharmacology of mesolimbic dopamine neurons: a dual-probe microdialysis study in the ventral tegmental area and nucleus accumbens of the rat brain. J Neurosci 16: 2605-2611.

Westerink BHC, Enrico P, Feimann J, De Vries JB (1998). The pharmacology of mesocortical dopamine neurons: a dual-probe microdialysis study in the ventral tegmental area and prefrontal cortex of rat brain. J Pharmacol Exp Ther 285: 143-154. 